\title{
RELAÇÃO ENTRE TIPOS DE TEMPO, EVENTOS DE PRECIPITAÇÃO EXTREMA E INUNDAÇÕES NO ESPAÇO URBANO DE SÃO SEPÉ -RS
}

\author{
Renata Dias Silveira ${ }^{10}$ \\ Maria da Graça Barros Sartori ${ }^{11}$
}

\begin{abstract}
RESUMO
O trabalho tem como objetivo relacionar os eventos de precipitação pluvial extrema com a ocorrência de inundações na zona urbana de São Sepé - RS, no período de 1980-2006. Para analisar a distribuição temporo-espacial da precipitação na área urbana, bem como sua variação sazonal, optou-se pela instalação de 4 pluviômetros, confeccionados de forma artesanal. A coleta dos dados do pluviômetro foi realizada no período de 1 ano escolhendo-se o mês mais representativo de cada estação do ano como amostra. Através do cruzamento dos eventos pluviais extremos encontrados na análise dos dados meteorológicos com os episódios de inundações noticiados pela imprensa local foram selecionados sete episódios de maior impacto no espaço urbano. Com base na análise dos episódios observou-se que volume mínimo de precipitação capaz de originar esse tipo de impacto é de $38 \mathrm{~mm}$ registrado em 24 horas e o volume máximo de precipitação registrado em 24 horas foi de $121,8 \mathrm{~mm}$. Quanto à intensidade da precipitação verifica-se que as inundações só ocorrem quando as precipitações são moderadas a fortes ou de intensidade superior (forte e muito forte). As precipitações moderadas são suscetíveis de causar inundações apenas se acompanhadas de intensidades menores. As inundações puderam ser distribuídas em 3 grupos quanto à gênese do episódio que lhes deu origem: inundações relacionadas a passagens frontais rápidas; inundações relacionadas a frentes estacionárias e inundações relacionadas à atuação conjunta de instabilidades tropicais e frentes polares. Quanto às repercussões das inundações no espaço urbano, em todos os episódios analisados ocorreram danos tais como a invasão das casas pelas águas e moradores desabrigados, além de danos materiais como a perda total ou parcial dos imóveis e pontes e danificação das vias urbanas. Por fim procurou-se espacializar as áreas suscetíveis a inundações bem como aquelas áreas que podem vir a ser atingidas por inundações à medida que a urbanização se intensificar.
\end{abstract}

Palavras-chave: clima urbano, precipitação, inundação, circulação atmosférica, tipos de tempo

\footnotetext{
${ }^{10}$ Mestre em Geografia- PPGGEO/UFSM, Doutoranda em Geografia - PPGG/FCT-UNESP- Presidente Prudente/ e-mail: renatasilveira82@gmail.com

${ }^{11}$ Doutora em Geografia, Professora do PPGGEO/UFSM/ e-mail: magracas@base.ufsm.br
} 


\section{ABSTRACT}

The research has have the objective of relate the extreme stormwater precipitation events with the ocurrence of floading at the São Sepé city urban area, at the period from 1980 to 2006. In order to analyze the time-space precipitation on the urban area, as well as its seasonal variation. It was decide for the instalation of four rain gauges, made by craftwork form. The datas collects from the rain gauges were made between the period of one year and was chosen the most representative mounth of each season as sample. Through the datas crossing of the extreme stormwater events reported by local press were chosen seven floading cases which had the most impact at the urban area. Using as parameter the cases analyzes was noticed the level of precipitaion capable of criate this sort of impact is at least $38 \mathrm{~m} \mathrm{~m}$ noted in 24 hours and the large precipitation volume noted in 24 hours was $121,8 \mathrm{~m} \mathrm{~m}$. The intensity of precipitation check that the floading only occur when the the precipitations are from averages to strong or with an intensity upper ( strong and stronger). The averages precipitations are susceptible of causing floading only if followed of minor intensities. The floading could been distributed in three groups according the episode beggining ; floading conected to fast frontal passages; floading conected to local fronts and floading conected to the acting of joint tropicals instability and pollars fronts. As much as the floading repercussion of urban area, all the cases analyzed ocurred damage as like as the invasion of houses by the water causing homeless people, besides material damages like total or partial lost of property and bridges and also the danification of rubans ways. Finally, was look forward to establish the susceptibles areas to floading as well as that aeras that might been reached by floadings in measure the urbanization grows.

Key words: urban climate, preciptation, floading, atmospheric circulation, weather types

\section{INTRODUÇÃO}

A ação do homem no espaço faz com que as condições do sistema natural sejam alteradas, o que irá desencadear novos processos, em um sistema de retroalimentação, uma vez que a natureza não é passiva às intervenções do homem.

O espaço urbano representa uma das maiores expressões das transformações provocadas pelo homem na paisagem natural. Essa natureza humanizada, vinculada a impermeabilização do solo, ocupação desordenada, retirada da cobertura vegetal, entre outros fatores, tendem a modificar os processos naturais, que muitas vezes acabam afetando de forma direta os habitantes.

O século XX foi considerado o 'século da urbanização', enquanto o século XXI, por sua vez, será o 'século da cidade'. Nesse contexto, em países como o Brasil, a urbanização de forma completamente desordenada se intensificou após a década de 1950 (fim da $2^{\circ}$ Guerra Mundial), associada ao acirramento do 
êxodo rural. Essa expansão desorganizada faz com que hoje as cidades, no geral, apresentem graves problemas físicos e sociais (MENDONÇA, 1994, 2004).

Contudo, apesar dos avanços tecnológicos da sociedade moderna, ela permanece bastante vulnerável aos eventos naturais extremos, de origem climática, hidrológica e geológica. No Brasil os eventos de maior repercussão são aqueles de natureza climática, como os eventos pluviais extremos (negativos e positivos), pois a relação clima-sociedade obedece, de acordo com Conti (1998), uma dialética onde os sistemas atmosféricos globais são organizados a partir de escalas superiores em relação às inferiores, enquanto a ação da sociedade evolui de forma inversa, das escalas inferiores para as superiores.

Uma sociedade torna-se mais vulnerável ao clima na medida em que sua economia depender dos fatores climáticos e quanto menos preparada estiver para lidar com os eventos climáticos adversos. Embora esses fenômenos sejam naturais, originados pelas disritmias dos sistemas meteorológicos, a ação antrópica, principalmente nas áreas urbanas, vem contribuindo para sua maior frequência, agressividade e expansão areolar (GONÇALVES, 2003).

Desse modo, dentre os elementos naturais o clima assume importância no que se refere à questão ambiental das cidades, pois fenômenos como precipitação, vento, temperatura e umidade relativa podem ser modificados pela conformação e estrutura do sítio urbano. O clima urbano consiste na alteração do clima local, imposto pela materialidade física das cidades e das atividades dela decorrentes, que acabam promovendo alterações nos balanços energético, térmico e hídrico (MONTEIRO; MENDONÇA, 2003). Essas alterações podem originar fenômenos como as ilhas de calor e de frescor, desconforto térmico, concentração da poluição e inundações (MENDONÇA, 2000).

As inundações relacionadas a episódios pluviais intensos, estas são favorecidas pela ocupação irregular das áreas marginais dos cursos d'água, associadas ao uso do solo urbano, predominantemente impermeabilizado. Dessa forma, torna-se relevante o monitoramento da precipitação em áreas urbanas, que pode sofrer alterações no tempo e no espaço em relação ao espaço rural (LANDSBERG, 1956 apud GRILLO;BRINO, 1994).

A circulação atmosférica do Rio Grande do Sul, por situar-se numa área climaticamente de transição, conta com a participação tanto dos sistemas atmosféricos extratropicais, quanto daqueles intertropicais, apesar dos primeiros controlarem os tipos de tempo do estado. O confronto periódico desses sistemas proporciona sucessivas passagens frontais, o que permite a ocorrência de precipitações bem distribuídas ao longo do ano. Porém, os sistemas de circulação atmosféricos estão sujeitos a alterações, o que pode ocasionar "episódios de longas estiagens ou de enchentes, que podem acontecer em qualquer época do ano" (SARTORI, 2003, p.28).

Os desvios de precipitação, tanto aqueles referentes a episódios pluviais intensos como períodos de estiagem, são extremamente impactantes na área urbana, onde concentra-se $80 \%$ da população brasileira. De acordo com Monteiro (1976) a escassez de precipitações repercute negativamente na cidade, podendo levar a crises de abastecimento e energia. Porém são os aguaceiros, fortes impactos pluviais concentrados, o problema de especial interesse no Brasil, uma vez que diferentes regiões ou algumas cidades podem ser violentamente prejudicadas em certas épocas do ano. 
A deterioração das cidades em seus vários aspectos tem motivado estudos, principalmente em áreas metropolitanas e cidades de grande porte, o que não significa, todavia, a ausência de problemas nas cidades médias e pequenas.

As cidades de porte médio e pequeno, segundo Mendonça (2000), apresentam características geográficas diferentes daquelas de grande porte e das metropolitanas, o que proporciona uma fácil identificação de suas particularidades. Todavia, percebe-se uma considerável carência no que se refere aos subsídios que permitam o tratamento específico de cidades de porte médio e pequeno. Cabe destacar que as aglomerações com mais de 20 mil habitantes, outrora chamadas de médias, são as que cresceram mais depressa, se comparado à população total e a população urbana, até pelo menos 1980 (SANTOS, 1996). Esse fato exige que propostas de estudos de clima urbano se voltem a esses núcleos.

A escolha pelo canal do Impacto Meteórico, dentre os subsistemas do Sistema Clima Urbano (SCU), justifica-se pelos constantes episódios de inundações na área urbana de São Sepé. Elas ocorrem, principalmente, pelo transbordamento do Lajeado do Moinho, afluente do Rio São Sepé, que drena parte do centro da cidade e cerca de três bairros, no setor oeste e norte. Suas margens, pela expansão urbana, vêm sendo intensamente ocupadas para fins imobiliários.

Essa ocupação desordenada, que acarreta impermeabilização e assoreamento das margens, retirada da vegetação nativa, juntamente com o acúmulo de lixo e lançamento de esgoto no leito do Lajeado, faz com que as inundações sejam frequentes. Na periferia da cidade (setor Nordeste), o Rio São Sepé também tem sua planície aluvial ocupada para moradias, principalmente por pessoas de baixa renda, o que aumentou consideravelmente nas décadas de 1980 e 1990.

Os episódios de inundações, constantemente noticiados pela mídia local, trazem consequências diretas à população ribeirinha, bem como gastos à administração municipal. Assim, torna-se indispensável mapear estas e outras possíveis áreas de risco, além de conhecer a gênese e características das precipitações responsáveis por inundações.

O presente trabalho tem como objetivo principal relacionar os eventos de precipitação pluvial extrema com a ocorrência de inundações na zona urbana de São Sepé - RS, no período de 1980-2006. Para tanto buscou-se identificar áreas suscetíveis aos impactos ambientais provocados por eventos de precipitação pluvial extrema, principalmente no que se refere a inundações, em função dos fatores geoecológicos e geourbanos.

Além disso, procurou-se conhecer as características dos eventos pluviais extremos quanto ao volume e intensidade da precipitação bem como os sistemas atmosféricos aos quais estão associados. Buscou-se ainda definir os tipos de tempo favoráveis a episódios de precipitação pluvial elevada e associar os eventos pluviométricos extremos com as inundações no perímetro urbano, de acordo com os registros da mídia local (jornais), e suas repercussões socioeconômicas. 


\section{MATERIAL E MÉTODOS}

As etapas para o desenvolvimento do trabalho baseiam-se em Monteiro (1976), quando este propõe o Sistema Clima Urbano (SCU), mais especificamente ao terceiro Canal de Percepção do Clima Urbano que corresponde ao Impacto Meteórico. Concomitantemente, utilizou-se a metodologia proposta por Mendonça (1994) no estudo do clima urbano de cidades de porte médio e pequeno.

Como etapa inicial buscou-se o reconhecimento do espaço urbano, uma vez que o sítio sobre o qual está assentada a cidade é algo peculiar, por sua capacidade de produzir repercussões nas esferas lito-biológicas e na atmosfera. O embasamento cartográfico elaborado para a caracterização do sítio urbano de São Sepé (aspectos geoecológicos) e suas derivações (aspectos geourbanos) foi composto de 5 cartas: cartas geomorfológica, de declividade, orientação de vertentes, uso da terra. As quatro primeiras abrangeram o espaço urbano e seu entorno, não apenas pela importância da inserção do ambiente urbano no espaço local/regional, como também pela falta de documentos cartográficos de escala maior, que servissem de base mais precisa. A apresentação final destes documentos tem escala aproximada de 1:80000.

Para a elaboração destes documentos cartográficos utilizou-se o software SPRING 4.0, composto também pelo programa IMPIMA 4.0, SCARTA 4.0 e IPLOT 4.0. Para a apresentação final utilizou-se o programa Corel Draw 10. O quinto documento refere-se à carta de uso do solo urbano, numa escala maior, com o objetivo principal de ressaltar a função urbana, digitalizado no programa Corel Draw 10.

A terceira etapa consistiu na confecção e instalação dos pluviômetros, pois de acordo com Monteiro (2003), a pesquisa de aspectos do clima da cidade exige uma observação meteorológica específica, que revele o que a observação padronizada procura evitar.

Para analisar a distribuição temporo-espacial da precipitação na área urbana de São Sepé, bem como sua variação sazonal, optou-se pela instalação de pluviômetros. A rede pluviométrica, composta por 4 pluviômetros, foi confeccionada de forma artesanal. Para a confecção dos mesmos baseou-se na metodologia sugerida por Collischonn (2002) e Machado et al (2004), com algumas adaptações.

Ao se considerar o porte da cidade em estudo, optou-se por um total de quatro pluviômetros distribuídos pela área urbana:

PONTO 1: Setor Noroeste - Rua Augusto César Pires Mota, no 2060 Bairro Lôndero

PONTO 2: Setor Leste - Rua João Tomás Soares Leal, no 90 - Bairro Santo Antônio

PONTO 3: Setor Central - Rua Percival Brenner n 1316 - Centro

PONTO 4: Setor Sul - Rua Cícero Brenner n 1284 - Bairro Izolanda

A coleta dos dados do pluviômetro foi realizada sazonalmente, no período de 1 ano (2005-2006), escolhendo-se o mês mais representativo de cada estação do ano como amostra: Primavera - outubro de 2005; Verão - janeiro de 2006; Outono - abril de 2006; Inverno - julho de 2006.

Os horários de coleta nos quatro meses de observação atendem aos recomendados pela OMM, ou seja, 9 horas, 15 horas e 21 horas (hora local). 
Nos meses de outubro e janeiro em função do horário de verão as coletas passaram a ser feitas às 10 horas, 16 horas e 22 horas.

Devido a irregularidade da coleta em certos meses em alguns pontos, os dados correspondentes deixaram de ser considerados. No mês de outubro de 2005 foram considerados os dados obtidos nos 4 pontos de coleta, já nos meses de janeiro e abril de 2006 o Ponto 1 deixou de ser utilizado, pois notou-se certa irregularidade na coleta por parte do observador encarregado. No mês de julho observou-se também grande discrepância entre os registros, por isso optou-se por considerar apenas o Ponto 4 como referência, pois apresentou maior precisão na coleta.

A coleta e análise dos dados meteorológicos e das notícias da imprensa local correspondem à quarta etapa do trabalho. Os dados meteorológicos utilizados foram os da Estação Meteorológica de Santa Maria (EMSM), pertencente ao Instituto Nacional de Meteorologia (INMET) referente ao período de 1980-2006, já que o município de São Sepé não possui estação meteorológica oficial. Além disso, os resultados baseiam-se nos dados de precipitação coletados através dos pluviômetros artesanais instalados na área urbana.

Tendo os meses representativos de cada estação do ano como base outubro de 2005, janeiro, abril e julho de 2006 procurou-se através da análise rítmica, conforme proposta de Monteiro (1971), conhecer a sucessão dos tipos de tempo e os sistemas atmosféricos atuantes

em cada mês. Os dados meteorológicos utilizados foram os da Estação Meteorológica de Santa Maria.

Através dos dados de precipitação coletados nos 4 pontos de coleta distribuídos pela área urbana de São Sepé procurou-se analisar a distribuição da precipitação no espaço urbano bem como traçar uma comparação entre a precipitação em São Sepé e Santa Maria durante esses meses.

De acordo com Souza e Sant'Anna Neto (2004), a análise quantitativa dos elementos meteorológicos não é suficiente para se identificar os episódios climáticos extremos, uma vez que nem sempre os episódios mais excepcionais do ponto de vista climático são aqueles que causam os maiores impactos. A imprensa, nesse contexto, surge como forma de incorporar elementos qualitativos, baseados em acontecimentos reais à análise meteorológica desses episódios. Concordando com essa idéia, buscou-se informações na imprensa local representados pelos jornais A Palavra (fundado em 1950), referentes aos 26 anos de estudo, e A Fonte somente a partir do ano de 2000 (fundação do jornal). As notícias levantadas foram aquelas que se referiam a impactos pluviais na área urbana de São Sepé entre 1980-2006.

Através do cruzamento dos eventos pluviais extremos encontrados na análise dos dados meteorológicos com os episódios de inundações noticiados pela imprensa, surgiram episódios significativos. Nesse cruzamento foram identificados 11 episódios de relevância, dentre os quais foram escolhidos sete, por serem os de maior impacto no espaço urbano: 05 a 07/05/1984 (Episódio 1); 21/05/1984 (Episódio 2); 12 e 13/04/1992; 13 a 17/10/1994; 16/12/1994 (Episódio 3); 27 e 28/12/1997 (Episódio 4); 30/09/2001; 19/09/2002; 03/10/2002 (Episódio 5); 19/02/2003 (Episódio 6); 10 e 11/09/2005 (Episódio 7).

Através da análise rítmica (Monteiro, 1971) e das repercussões junto à imprensa local procurou-se conhecer os tipos de tempo responsáveis pela 
ocorrência desses eventos pluviais extremos e as características desses episódios. A análise rítmica dos sete episódios contemplou não apenas o(s) dia(s) em que ocorreu o impacto como também os dias anteriores e posteriores, para que fosse possível a compreensão da sucessão dos tipos de tempo.

$\mathrm{Na}$ análise rítmica desses episódios bem como dos meses de outubro de 2005, janeiro, abril e julho de 2006 considerou-se a variação diária dos elementos como a pressão atmosférica (às12h GMT), umidade relativa (às $12 \mathrm{~h}$ e às 18h GMT), temperatura (máxima e mínima), insolação (total de horas), precipitação (mm totais), vento (direção e velocidade às $12 \mathrm{~h}, 18 \mathrm{~h}$ e $24 \mathrm{~h}$ GMT), nebulosidade ( $12 \mathrm{~h}, 18 \mathrm{~h}$ e $24 \mathrm{~h}$ GMT) e sistemas atmosféricos atuantes em cada dia. Para a identificação dos sistemas atmosféricos utilizou-se cartas sinóticas da Marinha do Brasil, disponíveis no site <www.dhn.mar.mil.br> e imagens do satélite GOES 12 para a América do Sul, projeção cilíndrica, no canal visível e infravermelho, disponíveis no site <www.cptec.inpe.br>.

Para maior compreensão do comportamento da precipitação durante os eventos de precipitação extrema procurou-se identificar a intensidade horária da chuva, através da definição de classes de intensidade (Quadro 1). As classes foram definidas através do método de Sturges.

Quadro 1. Classes de precipitação e intensidades correspondentes
\begin{tabular}{|c|c|}
\hline CLASSES DE PRECIPITAÇO & INTENSIDADE \\
\hline $0,1-12 \mathrm{~mm}$ & muito fraca \\
\hline $12,1-24 \mathrm{~mm}$ & Fraca \\
\hline $24,1-36 \mathrm{~mm}$ & Moderada \\
\hline $36,1-48 \mathrm{~mm}$ & moderada a forte \\
\hline $48,1-60 \mathrm{~mm}$ & Forte \\
\hline Maior que $60 \mathrm{~mm}$ & extremamente forte \\
\hline
\end{tabular}

Org.: SILVEIRA,R.D.

Com base na análise detalhada dos episódios selecionados foi possível caracterizá-los quanto ao volume e intensidade de precipitação como condição à ocorrência de inundações. Procurou-se, ainda, classificar os episódios quanto à sua gênese e associá-los aos fenômenos El Niño e La Niña.

Por fim, na quinta etapa procurou-se espacializar as áreas suscetíveis à inundações, bem como aquelas áreas que podem vir a ser atingidas à medida que a urbanização se intensificar. Essa carta foi elaborada a partir da caracterização dos episódios de inundação ocorridos na área urbana de São Sepé entre 1980-2006 e da análise integrada das cartas geomorfológica, de declividade, orientação de vertentes, uso da terra da área urbana e seu entorno e da carta-esboço do uso do solo urbano.

\section{ANÁLISE E DISCUSSÃo DOS RESULTADOS}

3.1 Episódios de inundações mais significativos entre 1980-2006 no espaço urbano de São Sepé - RS

Tendo por base os sete episódios de inundação selecionados nota-se que o volume mínimo de precipitação capaz de originar esse tipo de impacto é de 38 
$\mathrm{mm}$ registrado em 24 horas (Episódio 5). No outro extremo, o volume máximo de precipitação registrado em 24 horas foi de 121,8 mm durante o Episódio 2 .

Quanto à intensidade da precipitação verifica-se que as chuvas muito fracas (1 a $12 \mathrm{~mm}$ ), fracas $(12,1$ a $24 \mathrm{~mm}$ ) e moderadas (24, 1 a $36 \mathrm{~mm}$ ), desde que registradas isoladamente, não são capazes de provocar inundações. As inundações passam a ocorrer quando as precipitações são de moderadas a fortes $(36,1$ a $48 \mathrm{~mm}$ ) ou de intensidade superior (forte e muito forte), como pode ser visto nos episódios 2, 3, 5 e 7. As precipitações moderadas também são suscetíveis de causar inundações desde que acompanhadas de intensidades menores (Episódios 1, 4 e 6).

Outros fatores, porém, influenciam no volume e intensidade capazes de causar inundações como, por exemplo, a ocorrência de precipitações em dias anteriores, o que contribui para que o solo esteja saturado e o nível dos cursos d'água elevados.

\subsubsection{Inundações relacionadas a passagens frontais rápidas}

Nesse tipo de evento pluviométrico inserem-se os episódios de inundação 3 (16/12/1994), 4 (27 e 28/12/1997), 5 (03/10/2002) e 7 (10 e 11/09/2005), que foram caracterizados pela ocorrência de precipitações de significativa intensidade em curto espaço de tempo. No caso do Episódio 7 a FPA chega ao estado na metade do dia 10 e se afasta já no início do dia 11, o que caracteriza o rápido deslocamento do sistema frontal. Esse tipo de precipitação proporciona a lavagem do solo e a rápida elevação dos níveis dos cursos d'água, principalmente se estes estiverem obstruídos ou forem de pequeno porte.

O aspecto tempestuoso da precipitação está associado ao rápido deslocamento da frente polar sobre o Rio Grande do Sul, que pode ocorrer em qualquer época do ano, dependendo da intensidade do sistema polar à sua retaguarda. O tipo de tempo definido por essa característica de deslocamento do sistema frontal é o "Tempo Frontal de Sudoeste de Atuação Moderada".

\subsubsection{Inundações relacionadas a frentes estacionárias}

Corresponde aos episódios 1 (05 a 07/05/1984) e 2 (21/05/1984), nos quais a permanência da Frente Polar Atlântica sobre o estado durante vários dias proporciona grande volume de precipitação, o que contribui para o encharcamento do solo e consequente elevação dos níveis dos cursos d'água. No Episódio 2 nota-se a permanência do sistema frontal estacionário no Estado durante os dias 19 e 22, embora fossem registradas inundações apenas no dia 21. O tipo de tempo imposto por essas características é o "Tempo Frontal Estacionário".

3.1.3 Inundações relacionadas a atuação conjunta de instabilidades tropicais e frentes polares

O episódio 6 (19/02/2003) corresponde a essas características, quando a atuação da instabilidade tropical ocorre concomitantemente à chegada de uma frente fria, atraída pela baixa pressão imposta pela aproximação da descontinuidade frontal. As precipitações originadas da instabilidade, nesse 
caso, são seguidas por aquelas de origem frontal, proporcionando intensa precipitação em curto espaço de tempo.

3.2 Distribuição da precipitação no espaço urbano de São Sepé - RS e sistemas atmosféricos atuantes nos quatro meses representativos de cada estação do ano

Além da seleção e análise de episódios de inundação, buscou-se caracterizar as precipitações no espaço urbano de São Sepé, no que se refere à sua distribuição temporal e espacial. Foram escolhidos quatro meses representativos de cada estação do ano, durante os quais foram coletados dados de precipitação através de pluviômetros artesanais em quatro pontos da área urbana. Procurou-se, ainda, conhecer a sucessão dos tipos de tempo nesses quatro meses representativos de cada estação do ano, tendo por base os dados climáticos da EMSM.

O mês de outubro de 2005 foi caracterizado pelo domínio absoluto dos sistemas extratropicais, representado pela MPA. Os sistemas frontais bem definidos, a atuação de frentes estacionárias e frentes quentes originaram grande volume de precipitações. Na área urbana de São Sepé, assim, foram registrados altos índices de precipitação em todos os pontos de coleta (acima de $200 \mathrm{~mm}$ ) e a distribuição espacial apresentou-se bem homogênea.

Em janeiro de 2006 os sistemas extratropicais se fizeram presentes em maior número de dias, porém na forma de MPV, já que a MPA chega ao estado sem suas características originais de pressão e temperatura. As frentes frias se apresentaram, no geral, mal definidas, dissipando-se ou desviando para o oceano ao chegar na latitude do Rio Grande do Sul. As precipitações, todavia, foram significativas durante o mês, por ocasião de frentes estacionárias e instabilidades tropicais. Por esse motivo, de acordo com os dados coletados em São Sepé, esse mês se destacou dentre os quatro, não só pela diferença dos valores de precipitação entre os pontos, como pela descontinuidade espacial.

No mês de abril de 2006, os sistemas extratropicais se mostraram melhor definidos em relação ao mês de janeiro e a atuação da MPA, assim, torna-se mais freqüente, embora a MPV ainda domine na maior parte dos dias. Os sistemas frontais apresentaram-se, no geral, mal definidos e com rápidas passagens sobre o estado, o que contribuiu para o reduzido volume de precipitação registrado nesse mês. Dessa forma, o mês de abril apresentou-se como o menos chuvoso dentre os quatro meses, mas, da mesma forma que outubro, manteve certa homogeneidade no volume e distribuição espacial.

No mês de julho de 2006 a MPA aumentou sua participação e tempo de permanência sobre o estado. Além disso, houve maior frequência de frentes estacionárias e frentes quentes em relação ao outono devido intensificação do ATA, ao mesmo tempo em que os anticiclones polares estiveram mais bem definidos. Nesse mês não foi possível verificar a distribuição espacial da precipitação, pois somente Ponto 4 foi usado como referência.

Do ponto de vista da distribuição espacial da precipitação no espaço urbano de São Sepé, nos meses de janeiro e abril os menores valores de precipitação estão no Ponto 2, localizado a nordeste da área urbana. Esse fato possivelmente deve-se à sua posição, que o torna menos susceptível aos impactos do sistema frontal, em relação aos demais pontos. Além disso, esse ponto está em um nível de altitude mais baixo, próximo à planície aluvial do Rio São Sepé. 
Nos quatro meses analisados, o Ponto 4, posicionado ao sul da área urbana, apresentou o maior volume de precipitação, o que provavelmente está associado ao maior impacto das frentes frias sobre esse ponto, devido a sua localização e nível de altitude.

Com o intuito de verificar a aplicabilidade dos dados da EMSM ao se trabalhar com impactos pluviais na área urbana de São Sepé buscou-se uma análise comparativa entre os valores de precipitação registrados na estação e os dados de precipitação coletados na área urbana de São Sepé durante os meses em estudo. Observou-se, dessa forma, que o volume de precipitação foi maior em Santa Maria nos meses de outubro e janeiro enquanto em abril e julho os maiores índices foram registrados em São Sepé.

A maior discrepância no total de precipitação entre duas cidades foi encontrada no mês de janeiro, com $32 \mathrm{~mm}$ a mais em Santa Maria, e em julho, com 38,3 mm a mais em São Sepé. Percebe-se, portanto, nos meses amostrados, que não há tendência para que nenhuma das duas cidades seja mais ou menos chuvosa. Observa-se, nesse contexto, que as discrepâncias de valores de precipitação entre as duas cidades são insignificantes do ponto de vista da potencialidade de causar inundações.

Essa constatação está de acordo com Sartori (1979), que ao comparar a precipitação em três cidades (Júlio de Castilhos, Santa Maria e São Gabriel), notou relativa regularidade na distribuição e intensidade, uma vez que as chuvas estão quase sempre submetidas a uma mesma circulação, e quase a totalidade dos índices pluviométricos no Rio Grande do Sul estão associados a sistemas frontais.

De posse desses dados, verifica-se a aplicabilidade dos dados da Estação Meteorológica de Santa Maria para se identificar episódios de inundação na área urbana de São Sepé. As discrepâncias de valores de precipitação entre as duas cidades são insignificantes do ponto de vista da potencialidade de causar inundações, pelo menos aquelas que resultam em maiores impactos.

\subsection{Relação entre os episódios de inundação e os fenômenos El Niño e La Niña}

No Rio Grande do Sul os totais pluviométricos e a distribuição das chuvas são afetados, por ocasião dos fenômenos El Niño e La Niña, uma vez que durante o primeiro há um incremento no número de dias com precipitação, enquanto no segundo há redução, (PUCHALSKI et al, 2001 apud BERLATO; FONTANA, 2003).

Partindo dessa afirmação, procurou-se relacionar a ocorrência de episódios de inundação na área urbana de São Sepé a esses fenômenos. Foram considerados na análise os 11 episódios de inundação encontrados ao se associar as notícias relacionadas a impactos pluviais veiculadas nos jornais locais aos dados de chuva da EMSM no período de 1980 a 2006 (Quadro 2). Pode-se perceber grande relação entre o fenômeno El Niño e a ocorrência de episódios de inundações, já que dos 11 episódios considerados entre os anos de 1980-2006, 9 deles ocorreram em meses em que se definiu esse fenômeno.

Com relação ao fenômeno La Niña não foi observada nenhuma relação, uma vez que durante sua atuação nenhum episódio de inundação foi registrado na área urbana de São Sepé. Os demais episódios - 30/09/2001 e 10 e $11 / 09 / 2005$ - ocorreram em anos neutros, ou seja, em que não foram sentidas a influência dessa anomalia. 
Quadro 2. Relação entre o fenômeno El Niño e La Niña e os episódios de inundação na área urbana de São Sepé.

\begin{tabular}{|c|c|c|}
\hline EPISÓDIO & EL NIÑO & LA NIÑA \\
\hline 05 a $07 / 05 / 1984$ & $X$ & \\
\hline $21 / 05 / 1984$ & $X$ & \\
\hline 12 e $13 / 04 / 1992$ & $X$ & \\
\hline 13 a $17 / 10 / 1994$ & $X$ & \\
\hline $16 / 12 / 1994$ & $X$ & \\
\hline 27 e $28 / 12 / 1997$ & $X$ & \\
\hline $30 / 09 / 2001$ & & \\
\hline $19 / 09 / 2002$ & $X$ & \\
\hline $03 / 10 / 2002$ & $X$ & \\
\hline $19 / 02 / 2003$ & & \\
\hline 10 e $11 / 09 / 2005$ & & \\
\hline
\end{tabular}

Fonte: Estação Meteorológica de Santa Maria; Jornais A Palavra e A Fonte. Org.: SILVEIRA,R.D.

\subsection{Espacialização das áreas suscetíveis a inundações na cidade de São Sepé}

Tendo por base a carta geomorfológica segundo a hipsometria percebese que o sítio urbano de São Sepé não está numa área de planície aluvial. De acordo com Tucci (1999, 2002), a ocupação dessas áreas, que são inundadas em média a cada dois anos, leva à inundação de áreas ribeirinhas. Esse tipo de inundação ainda é pouco comum em São Sepé, mas tende a tornar-se mais freqüente, devido à expansão irregular da urbanização em direção à planície aluvial do rio São Sepé (a nordeste da área urbana).

O tipo de inundação mais freqüente no sítio urbano de São Sepé é aquela associada à urbanização, que de acordo com Tucci (1999, 2002) ocorre pela impermeabilização do solo e desorganizada infra-estrutura urbana.

A partir da caracterização dos episódios de inundação ocorridos na área urbana de São Sepé entre 1980-2006 e da análise integrada das cartas geomorfológica, de declividade, orientação de vertentes, e de uso da terra do entorno da área urbana, além da carta-esboço do uso do solo na cidade, procurou-se espacializar as áreas mais suscetíveis a inundações. Além disso, foram identificadas aquelas áreas de risco, que podem vir a ser atingidas por inundações à medida que a urbanização se intensificar (Figura 1).

Pode-se verificar que as áreas mais atingidas são aquelas situadas às margens do Lajeado do Moinho e Rio São Sepé. Uma série de fatores contribui para que essas áreas sejam mais suscetíveis à inundações. O primeiro deles refere-se ao fato de que a área central da cidade está em um nível de altitude mais elevado, possui declividade praticamente nula, cujos valores aumentam em direção à periferia e vertentes sem orientação definida, servindo como dispersor de água em todas as direções. Além disso a impermeabilização desse setor contribui para o maior escoamento em direção às áreas mais baixas. 


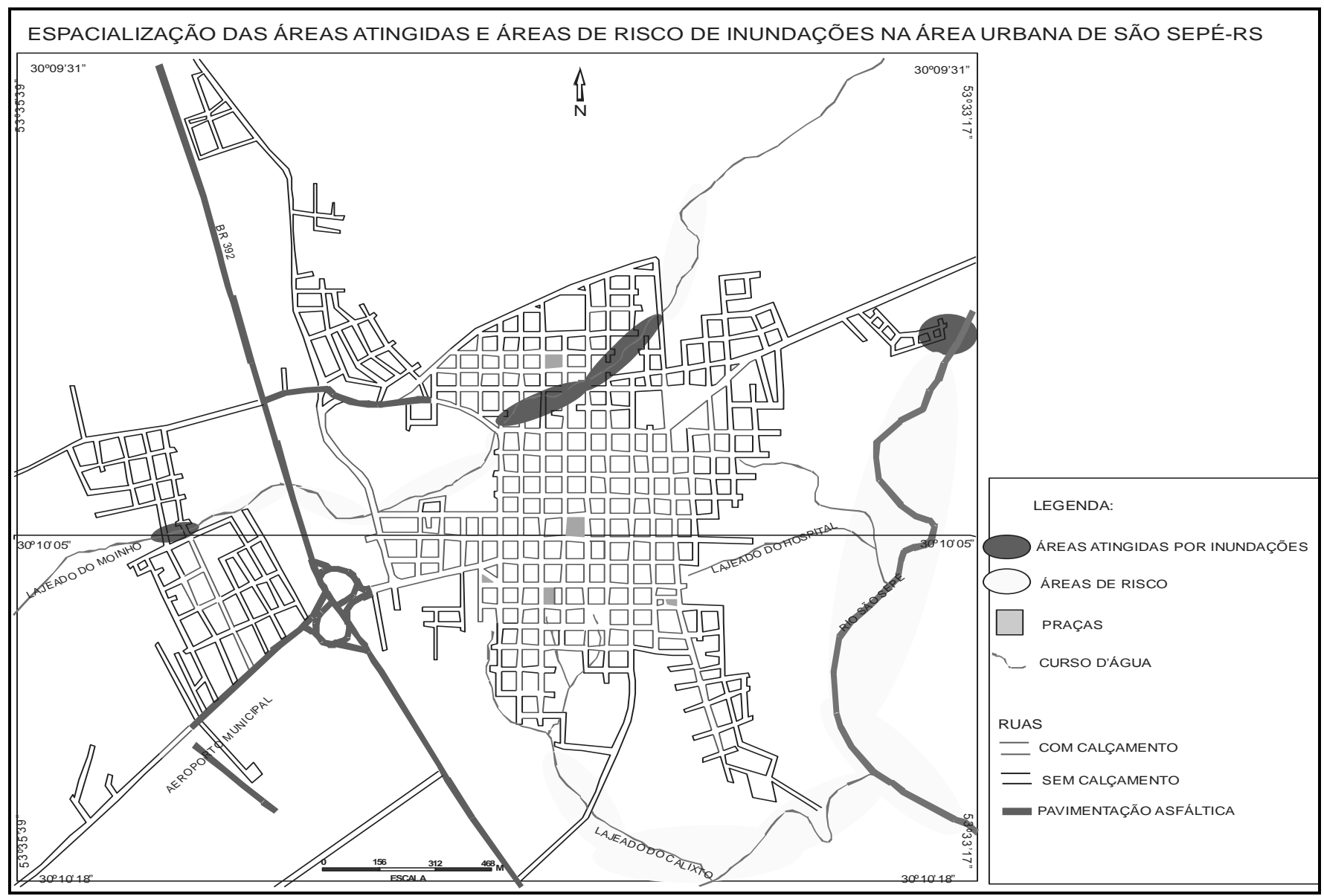

Figura 1. Espacialização das áreas atingidas e áreas de risco de inundações na área urbana de São Sepé -RS Fonte: Plano diretor - zoneamento de usos, 1982 e trabalho de campo Org. : SILVEIRA,R.D. 
Assim, durante um evento de impacto pluvial a água chega rapidamente aos canais, que por serem de pequeno porte, possuírem estreita planície aluvial, praticamente impermeabilizada e sem mata ciliar, acabam transbordando.

Os Bairros Santos e Pontes, situados a oeste do perímetro urbano são atingidos por inundações nas áreas situadas ao longo do Lajeado do Moinho. Esses bairros estão situados no compartimento geomorfológico denominado topo das coxilhas (altitudes maiores que $120 \mathrm{~m}$ ), que representa as maiores altitudes presentes na área urbana.

As declividades aí variam entre 5 e 12\%; quanto ao uso da terra e uso do solo urbano caracterizam-se por serem áreas urbanizadas para fins residenciais, sem a presença de mata ciliar ao longo das margens do canal fluvial, no limite entre os dois bairros, e com predominância de ruas sem pavimentação.

Já as áreas atingidas diretamente pelas inundações - às margens do Lajeado - situam-se no compartimento geomorfológico denominado transicional, cujas altitudes variam de 60 a $120 \mathrm{~m}$ e as declividades estão entre 12 e $30 \%$. Percebe-se por essas características que apenas por fatores naturais não se explica a ocorrência de inundações nesse ponto da área urbana, uma vez que, conforme as declividades e situação geomorfológica, essas áreas encontram-se próximas à nascente, ainda no alto curso do canal fluvial.

O que ocorre, não só nessa área como na maior parte dos setores atingidos por inundações na cidade é a modificação dos processos naturais, a partir da impermeabilização das margens juntamente com a retirada da cobertura original.

A área onde as inundações atingem maior continuidade espacial corresponde ao Bairro Kurtz, localizado ao norte da área urbana, no compartimento geomorfológico transicional, cujas altitudes variam de 60 a 120 m. Já as declividades na maior parte estão entre 12 e 30\%, principalmente nas áreas voltadas para o Lajeado do Moinho, enquanto nas partes mais elevadas bem como naquelas junto ao canal são inferiores a $5 \%$.

A expressiva urbanização que acompanha o Lajeado do Moinho neste bairro, ocupado para fins residenciais, associada à ausência de cobertura vegetal e impermeabilização do solo, são os responsáveis pela ocorrência desses impactos. Nota-se, nesse setor, uma planície aluvial mais expressiva em relação às áreas atingidas nos bairros Santos e Pontes, que vai tornando-se mais ampla em direção à foz. As inundações ao longo do Lajeado são agravadas ainda pelo fato de que em seu trecho não urbanizado (em direção às nascentes) o canal apresenta mata ciliar pouco expressiva e ocupação do solo para pastagens e lavouras.

O setor da área urbana atingido por inundações devido ao transbordamento do Rio São Sepé corresponde ao Bairro Cristo Rei, a nordeste do perímetro urbano. Esse bairro está situado entre os compartimentos geomorfológicos transicional e planície aluvial - menor que $60 \mathrm{~m}$ e as declividades estão abaixo de 5\%. Esse setor, embora naturalmente susceptível, só atualmente vem sendo atingido por inundações, pois a ocupação urbana ainda é recente.

Além disso, foram identificadas áreas suscetíveis a futuros episódios de inundações, desde que a urbanização continue avançando desordenadamente em direção aos cursos d'água e a impermeabilização das áreas já urbanizadas se intensifique. Nota-se, nessas áreas, a relativa ausência de cobertura vegetal e em algumas delas a urbanização já está presente, o que torna iminente o risco de impactos.

Uma dessas áreas corresponde a todo o trecho da área urbana ao longo do Lajeado do Moinho, que ainda não foi impermeabilizado, e cuja cobertura 
vegetal original não foi totalmente destruída. Os bairros abrangidos por essa área são Santos, Pontes, Rosa e São Francisco, porém já se nota o acúmulo de lixo às margens e no interior do canal fluvial. Além disso, mesmo que no Plano Diretor (1995) as áreas situadas ao longo da BR 392 sejam denominadas Área Especial, onde é permitido apenas o reflorestamento, cultivo de hortifrutigranjeiros e estacionamentos, nota-se tendência à ocupação urbana desse setor, ainda que de maneira lenta. O compartimento geomorfológico é o transicional e as declividades são inferiores a $5 \%$ na maior parte, o que mostra a susceptibilidade dessa área desde que a urbanização se intensifique.

As áreas situadas ao longo do Lajeado do Calixto, que drenam o sul do perímetro urbano, também podem, na medida em que a ocupação urbana se intensificar tornar-se sujeitas a inundações. As declividades nas suas nascentes, que estão na área urbana, são de 12 a 30\%, porém predominam aquelas inferiores a $5 \%$. O que deve ser destacado nesse setor e que pode levá-lo a ser atingido por inundações é que, mesmo sendo um canal de pequeno porte, a mata ciliar das nascentes do Lajeado do Calixto vem sendo continuamente destruída para fins de loteamento. Nota-se ainda, neste setor, a presença de estabelecimento comerciais como engenhos de arroz e olarias, além da expressiva expansão da área ocupada por moradias (Bairros Izolanda e Bela Vista).

Por fim, destacam-se as áreas situadas ao longo da estreita planície aluvial do rio São Sepé, cujas declividades estão entre 5 a $12 \%$ e inferiores a $5 \%$, nas áreas mais próximas ao rio. Além da expansão desordenada do Bairro Cristo Rei, que já é um fato, a possível expansão dos bairros Santo Antônio e Tatsch pode torná-los suscetíveis, uma vez que a planície aluvial já é inundada por eventos pluviais extremos, porém sem trazer danos à população até o presente momento.

\section{CONSIDERAÇÕES FINAIS}

No presente trabalho pretendeu-se estudar aspectos do clima urbano da cidade de São Sepé sob a ótica do canal de percepção referente ao impacto meteórico, uma vez que é o problema mais agravante à ordenação urbana.

Nessa perspectiva a caracterização do sítio urbano, da estrutura da cidade e sua dinâmica funcional demonstraram ser indispensáveis à caracterização dos episódios pluviais intensos, bem como à espacialização das áreas sujeitas a esses impactos pluviais. Confirma-se aqui a importância de se considerar os aspectos geoecológicos e geourbanos nos estudos do clima urbano.

Na seleção dos episódios de inundação mais significativos observou-se a importância da imprensa, nesse caso os jornais, na identificação de episódios pluviais extremos, uma vez que de acordo com Souza e Sant'Anna Neto (1998) nem sempre os episódios mais excepcionais do ponto de vista climático são aqueles que causam os maiores impactos. Assim, só a partir do cruzamento entre os dados meteorológicos e as notícias dos jornais foi possível estabelecer a relação entre precipitação e inundação na área urbana de São Sepé. Ressaltase, porém, a devida cautela a ser tomada quando se trabalha com dados da imprensa, pois algumas vezes os verdadeiros fatos podem ser omitidos ou supervalorizados. 
$\mathrm{Na}$ espacialização das áreas suscetíveis às inundações pode-se verificar que os pontos mais atingidos são aqueles situados às margens do Lajeado do Moinho e Rio São Sepé. O que deve ser destacado é que do ponto de vista natural essas áreas não deveriam estar sujeitas a esses impactos, mas são provocados pela ocupação humana.

Quanto às repercussões das inundações no espaço urbano, em todos os episódios analisados ocorreram danos, tais como a invasão das casas pelas águas e moradores desabrigados, além de danos materiais como a perda total ou parcial dos imóveis e pontes e danificação das vias urbanas. Os episódios 1 e 2, ocorridos em maio de 1984 foram os de maior volume total de precipitação e impactos, o que permite afirmar que nenhuma anomalia na precipitação vem acontecendo no presente, no sentido de contribuir para o aumento no volume das chuvas ou para a ocorrência de impactos maiores nas áreas ribeirinhas.

O que se nota, no entanto, é o maior número de episódios significativos registrados pelos jornais a partir da década de 1990, mesmo que com menores volumes de chuvas e repercussões com relação aos ocorridos na década de 80 . Esse fato possivelmente está associado à evolução dos meios de comunicação, nesse caso os jornais, que dispõem hoje de maiores recursos materiais e humanos, além de que atualmente a imprensa vem dando ênfase às questões urbanas e ambientais.

A definição e caracterização dos episódios pluviais intensos, no que se refere à gênese, intensidade e volume de chuva, mesmo que de forma preliminar, poderão servir de base para prevenção desses impactos bem como para estudos posteriores. A partir da definição das áreas sujeitas às inundações bem como daquelas que futuramente poderão ser vulneráveis pretende-se contribuir ao planejamento urbano de São Sepé no sentido de auxiliar na organização e utilização racional do espaço urbano, procurando minimizar os impactos daquelas áreas constantemente atingidas, bem como evitar que novas áreas venham a ser afetadas por inundações. Pretende-se, dessa forma contribuir para que haja melhoria da infra-estrutura urbana e da qualidade de vida da população.

\section{REFERÊNCIAS}

ALVES FILHO, A.P. Episódios pluviais intensos na Região Metropolitana de São Paulo: uma avaliação do decênio 1982-1991. 1996. Dissertação (Mestrado em Geografia Física) - Universidade de São Paulo, São Paulo, 1996.

AYOADE, J.O. Introdução à climatologia para os trópicos. São Paulo: Difel, 1986.

AZEVEDO, T.R. Distribuição espacial da chuva: um ensaio metodológico. In.: TARIFA, J.R. AZEVEDO, T.R. de. Os climas na cidade de São Paulo. São Paulo: USP/FFLCH/Laboratório de Climatologia, 2001. p.155-164. (GEOUSPColeção Novos Caminhos-4) 
Berlato, M. A; FONTANA, D.C. El Niño e La Niña: impactos no clima, na vegetação e na agricultura do Rio Grande do Sul. Porto Alegre: Ed. da UFRGS, 2003.

BRAGA, B.P.F. Controle de cheias urbanas em ambiente tropical. In.: BRAGA, B.P.F.; TUCCI, C.E.M.; TOZZI, M. Drenagem urbana: gerenciamento, simulação e controle. Porto Alegre: ABRH/ ed. Da UFRGS, 1998.

BRANDÃO, A .M. P. M. Clima urbano e enchentes na cidade do Rio de Janeiro. In.: GUERRA, A.J.T; CUNHA, S. B. Impactos ambientais urbanos no Brasil. Rio de Janeiro: Bertrand Brasil, 2001.

BOTELHO, R. G. M; SILVA, A. S. Bacia hidrográfica e qualidade ambiental. In: VITTE, A. C; GUERRA, A. J. T. Reflexões sobre a geografia física no Brasil. Rio de Janeiro: Bertrand Brasil, 2004.

CERRI, L. E.S. Riscos geológicos urbanos. In.: CHASSOT, A.; CAMPOS, H. (orgs). Ciências da terra e meio ambiente: diálogos para (inter) ações no planeta. São Leopoldo: Ed. da UNISINOS, 1999.

COLISCHONN, E. Variação temporal e especial da precipitação: uma experiência didática. In: V SIMPÓSIO BRASILEIRO DE CLIMATOLOGIA GEOGRÁFICA, 2002, Curitiba. Anais... Curitiba: UFPR, 2002. p.1130-1138. 1 CD-ROM.

CONTI, J. B. Clima e meio ambiente. 4. ed. São Paulo: Atual, 1998.

CUSTÓDIO, V. A persistência das inundações na Grande São Paulo. 2002. Tese (Doutorado em Geografia Humana) - Universidade de São Paulo, São Paulo, 2002.

DE BIASI, M. et al., 1977. Cartas de Orientação de Vertentes: confecção e utilização. Cartografia. Instituto de Geografia / USP. n.4. São Paulo, p. 2-11.

DE BIASI, M. A carta clinográfica: os métodos de representação e sua confecção. Revista do Departamento de Geografia. São Paulo: FFLCH/USP, n.6, 1992. p.45-60.

FERIGOLO,E. F.; VALMERATE, M.M.S.; SARTORI, M.G.B. As chuvas no Rio Grande do Sul e a explicação genética dos episódios de secas e enchentes no período de junho de 1979 a maio de 1985. Geografia - Ensino e Pesquisa. Santa Maria, n.1, dez.1987. p.39-68.

GONÇALVES, N. M. S. Impactos pluviais e desorganização do espaço em Salvador. In.: MONTEIRO, C.A.F.; MENDONÇA, F. (org). Clima urbano. São Paulo: Contexto, 2003.

GRILLO, R. C.; BRINO, W. C. O impacto da precipitação pluvial na cidade de Rio Claro-SP. Geografia. Rio Claro, v.19 n.1, abr. 1994. p.39-60. 
INFANTI JÚNIOR, N.; FORNASARI FILHO, N. Processos de dinâmica superficial. In: OlIVEIRA, A. M. dos S.; BRITO, S. N. A. de. Geologia de engenharia. São Paulo; Associação Brasileira de Geologia de Engenharia, 1998. p.131-152.

JACOBI, P. Impactos socioambientais urbanos: do risco à busca da sustentabilidade. In: MENDONÇA, F. (org.) Impactos socioambientais urbanos. Curitiba: Ed. da UFPR, 2004.

LANDSBERG, H. E. Man's role in changing the face of the earth. Chicago: The University of Chicago Press, 1956.

LANDSBERG, H. E. The urban climate. New York: Academic Press, 1981.

MACHADO, D. V. et al. Mapeamento pluvial: uma experiência didáticapedagógica para a Região Metropolitana do Rio de Janeiro. In: V SIMPÓSIO BRASILEIRO DE CLIMATOLOGIA GEOGRÁFICA, 2004, Aracaju. Anais... Aracaju: Núcleo de Pós-Graduação em Geografia/ UFS, 2004. 1 CD-ROM.

MENDONÇA, F.A. (org). Impactos socioambientais urbanos. Curitiba: ed. da UFPR, 2004.

MENDONÇA, F.A. O estudo do clima urbano no Brasil: evolução, tendências e alguns desafios. In: MONTEIRO, C.A.F.; MENDONÇA, F. (org). Clima urbano. São Paulo: Contexto, 2003.

. C Clima e o planejamento urbano de cidades de porte médio e pequeno: proposição metodológica para estudo e sua aplicação à cidade de Londrina-PR. 1994. 322f. Tese (Doutorado em Geografia)-Universidade de São Paulo, São Paulo, 1994.

MONTEIRO, C.A.F. Teoria e clima urbano: um projeto e seus caminhos. In: MONTEIRO, C.A.F.; MENDONÇA, F. (org). Clima urbano. São Paulo: Contexto, 2003.

. O estudo geográfico do clima. Cadernos Geográficos. Florianópolis, ano I, n.1, maio, 1999.

.Teoria e clima urbano. São Paulo: EDUSP, 1976. (Série Teses e Monografias, n.25).

. Análise rítmica em climatologia: problemas da atualidade climática em São Paulo e achegas para um programa de trabalho. Climatologia. São Paulo, n.1, 1971.

. A frente polar atlântica e as chuvas de inverno na fachada suloriental do Brasil. São Paulo: ed. da USP, 1969. (Série Teses e Monografias, n.1). 
.O Clima da Região Sul.In: Geografia Regional do Brasil: Região Sul. Rio de Janeiro: IBGE, v.4, p.117-169, $1963 a$.

OLIVEIRA, R. C. de. A problemática das enchentes e o planejamento urbano. Geografia. Rio Claro, v. 24, n. 2, 1999.

PASCHOAL, W. As inundações no Cambuci: percepção e reação do habitante e usuário de uma área central da metrópole a um de seus problemas mais sérios. 1981. Dissertação (Mestrado em Geografia) - Universidade de São Paulo, São Paulo, 1981.

PASTORINO, L.A. O problema das enchentes na região de São Paulo. Caderno de ciências da terra. São Paulo, n.19, 1971. p.1-36.

PREFEITURA MUNICIPAL DE SÃO SEPÉ. Lei no 2125, de 04 de maio de 1995. Lei do Plano Diretor. São Sepé, 1995, 106 p.

PREFEITURA MUNICIPAL DE SÃO SEPÉ. Plano diretor - zoneamento de usos, escala $1: 12500,1982$.

RAQUEL, R. et al. Correlação existente entre pluviômetro padrão e pluviômetros de menor custo. In: XIII CONGRESSO BRASILEIRO DE AGROMETEOROLOGIA, 2003, Santa Maria. Anais... Santa Maria: UNIFRA/ SBA, 2003. p.405-406.

RIBEIRO,A.G. As escalas do clima. Boletim de Geografia Teorética. Rio Claro, n. 23, v. 45-46, 1993. p.288-294.

RIO GRANDE DO SUL. Secretaria do planejamento e gestão. Atlas Socioeconômico do Rio Grande do Sul. Disponivel em: <http://www.scp.rs.gov.br/atlas>. Acesso em jan. 2006.

SANT'ANNA NETO, J.L. Clima e organização do espaço. Boletim de Geografia. Maringá, ano 16, n.1, p.119-131, 1998.

.História da Climatologia no Brasil. 2001. Tese (Livre Docência) Universidade Estadual Paulista, Presidente Prudente, 2001.

SANTIS, D.G.D.; MENDONÇA, F. de A. Inundações e seus impactos em áreas urbanas: o caso de Francisco Beltrão/PR. In: IV SIMPÓSIO BRASILEIRO DE CLIMATOlogiA GEOGRÁFICA, 2000, Rio de Janeiro. Anais... Rio de Janeiro: Climageo/UFRJ, 2000. 1 CD-ROM.

SANTOS, M. Manual de geografia urbana. São Paulo: HUCITEC, 1981.

SARTORI, M.G.B. A dinâmica do clima no Rio Grande do Sul: indução empírica e conhecimento científico. Terra Livre. São Paulo, ano 19, v.1, n.20, p.27-49. jan/jul.2003.

.Distribuição das chuvas no Rio Grande do Sul e a variabilidade temporo-espacial no período de 1912-1984. In: V SIMPÓSIO DE GEOGRAFIA 
FÍSICA APLICADA, 1993, São Paulo. Anais... São Paulo: Departamento de Geografia/FFLCH/USP, 1993. p.275 -280.

.As variações pluviométricas e o regime das chuvas na Região Central do Rio Grande do Sul. Boletim de Geografia Teorética. Rio Claro, n.23, vol. 45-46, 1993. p.70-84.

A Circulação atmosférica regional e os principais tipos de tempo no inverno do Rio Grande do Sul, Brasil. Ciência e Natura. Santa Maria, n15, p.69-93, 1993.

.O clima de Santa Maria, RS: do regional ao urbano. 1979. $166 \mathrm{fl}$. Dissertação (Mestrado em Geografia) - Universidade de São Paulo, São Paulo, 1979.

SILVEIRA, R.D; SARTORI, M.G.B; ROSA, J.L. Integração meio ambientecomunidade na sub-bacia hidrográfica Lajeado do Moinho, São Sepé-RS. In: X SIMPÓSIO DE GEOGRAFIA FÍSICA APLICADA, 2003, Rio de Janeiro. Anais... Rio de Janeiro: Departamento de Geografia/UERJ, 2003. 1 CD-ROM.

SOUZA, C. G.; SANT'ANNA NETO,J.L. Ritmo climático e eventos extremos no Oeste Paulista: a imprensa como fonte de informações geográficas. In: VI SIMPÓSIO BRASILEIRO DE CLIMATOLOGIA GEOGRÁFICA. 2004, Aracaju. Anais... Aracaju: Núcleo de Pós-Graduação em Geografia/ UFS, 2004. 1 CDROM.

TUCCI, C. E. M. Gerenciamento da drenagem urbana. Revista Brasileira de Recursos Hídricos. Porto Alegre, v.7, n.1, jan/mar, 2002.

Drenagem urbana e controle de inundações. In: CHASSOT, A.; $\overline{C A M P O S}, \mathrm{H}$. (orgs). Ciências da terra e meio ambiente: diálogos para (inter) ações no planeta. São Leopoldo: ed. da UNISINOS, 1999.

1993.

Hidrologia: ciência e aplicação. Porto Alegre, ABRH/ ed. da UFRGS,

ZAVATINI, J.A. A climatologia geográfica brasileira, o enfoque dinâmico e a noção de ritmo climático. Geografia. Rio Claro, v. 23, n. 3, p.5-24, dez.1998.

O tempo e o espaço nos estudos do ritmo do clima no Brasil. Geografia. Rio Claro,v. 27,n. 3, p.101-131, dez.2002. 
